\title{
BMJ Does mild cognitive impairment affect Open the occurrence of radiographic knee osteoarthritis? A 3-year follow-up in the ROAD study
}

\author{
Noriko Yoshimura, ${ }^{1}$ Shigeyuki Muraki, ${ }^{2}$ Hiroyuki Oka, ${ }^{1}$ Hiroshi Kawaguchi, ${ }^{3}$ \\ Kozo Nakamura, ${ }^{4}$ Sakae Tanaka, ${ }^{3}$ Toru Akune ${ }^{2}$
}

To cite: Yoshimura N, Muraki S, Oka H, et al. Does mild cognitive impairment affect the occurrence of radiographic knee osteoarthritis? A 3-year follow-up in the ROAD study. BMJ Open 2012;2:e001520. doi:10.1136/bmjopen-2012001520

- Prepublication history for this paper are available online. To view these files please visit the journal online (http://dx.doi.org/10.1136/ bmjopen-2012-001520).

Received 25 May 2012 Accepted 11 October 2012

This final article is available for use under the terms of the Creative Commons Attribution Non-Commercial 2.0 Licence; see http://bmjopen.bmj.com

For numbered affiliations see end of article.

Correspondence to Noriko Yoshimura; yoshimuran-ort@h.u-tokyo. ac.jp

\section{ABSTRACT}

Objective: To determine whether mild cognitive impairment $(\mathrm{MCl})$ increases the risk of occurrence or progression of radiographic knee osteoarthritis (KOA) in a general population.

Design: Population-based cohort study.

Setting: Residents in mountain and seaside areas of Wakayama Prefecture, Japan.

Participants: 1690 participants (596 men, 1094 women; mean age 65.2 years old) were enrolled from the large-scale cohort for the Research on Osteoarthritis (OA)/osteoporosis Against Disability (ROAD) study initiated in 2005 to investigate epidemiological features of OA in Japan. Of these, 1384 individuals (81.9\%; 466 men, 918 women) completed the second survey including knee radiography 3 years later.

Primary outcome measures: Radiographic KOA was defined as Kellgren-Lawrence $(\mathrm{KL})$ grade $\geq 2$ using paired $x$-ray films. Incidence of KOA during follow-up defined on radiographs as $K L$ grade $\geq 2$, progression of KOA defined as a higher KL grade (either knee) at follow-up compared with baseline. $\mathrm{MCl}$ defined as a summary mini-mental state examination (MMSE) score $\leq 23$. Associations between $\mathrm{MCl}$ and incidence or progression of KOA were analysed.

Results: The annual cumulative incidence of KOA was $3.3 \%$; for progression of OA it was $8.0 \%$. On logistic regression analysis adjusted for age, gender, regional differences, body mass index, grip strength (worse side), smoking, alcohol consumption, regular exercise and history of knee injury, baseline MMSE summary score was significantly associated with the incidence of KOA (+1 MMSE score; OR 0.83, $p=0.010$ ). Baseline $\mathrm{MCl}$ was also significantly associated with the incidence of KOA (vs non-occurrence of KOA; OR 4.90, $\mathrm{p}=0.027$ ). There was no significant association between MMSE scores, the presence of $\mathrm{MCl}$ and progression of KOA (+1 MMSE score; OR 0.96 , $p=0.232$; vs non-progression of KOA; OR 1.38 , $\mathrm{p}=0.416$ ).

Conclusions: $\mathrm{MCl}$ significantly increases the risk of incident radiographic KOA, but not the progression of KOA.

\section{ARTICLE SUMMARY}

\section{Article focus}

- Both cognitive impairment and osteoarthritis (OA) are top-ranked causes of disability requiring support, but there have been no previous reports on the association between cognitive impairment and $\mathrm{OA}$.

- We aimed to investigate the association between mild cognitive impairment (MCl) and the occurrence and progression of radiographic knee osteoarthritis (KOA) among men and women who participated in the Research on Osteoarthritis/osteoporosis against Disability (ROAD) study.

Key messages

- Of 1690 participants at the baseline, 1384 individuals (81.9\%; 466 men, 918 women) completed the second survey including knee radiography 3 years later.

- The annual cumulative incidence of radiographic KOA in these 1384 participants was 3.3\%; for progression of $\mathrm{KOA}$, it was $8.0 \%$.

- The prevalence of $\mathrm{MCl}$ in the 1384 participants defined as summary mini-mental state examination score $\leq 23$ was $4.5 \%$.

- Baseline mini-mental state examination (MMSE) summary score was significantly associated with the incidence of radiographic KOA after adjustment for confounders (+1 score; OR0.83, $\mathrm{p}=0.010$ ). Baseline $\mathrm{MCl}$ was also significantly associated with the incidence of radiographic KOA (vs non-occurrence of KOA; OR 4.90, $\mathrm{p}=0.027$ ). There was no significant association between MMSE scores, the presence of $\mathrm{MCl}$ and the progression of radiographic $\mathrm{KOA}(+1$ score; OR 0.96, $p=0.232$; vs non-progression of KOA; OR 1.38, $p=0.416$ ).

\section{INTRODUCTION}

Plural chronic diseases have a high prevalence in the elderly population. In the USA, about $77 \%$ of older adults have two or more chronic illnesses, and these can lead to 


\section{ARTICLE SUMMARY}

Strengths and limitations of this study

- The present study includes a population-based design of a cohort, large number of participants with KOA, and a 3-year follow-up with a high participation rate of $81.9 \%$.

- Substantial amount of detailed information, including an interviewer-administered questionnaire, dietary assessment, anthropometric measurements, neuromuscular function assessment, biochemical measurements, medical history, radiographic assessment and bone mineral density measurement, was collected at both the baseline and the second visit.

- We used $K L$ grade $\geq 2$ for the diagnosis of radiographic KOA, but the $\mathrm{KL}$ scale is a categorical index, and it might be impossible to evaluate the minimum joint space and osteophytosis separately.

- We used only the MMSE to diagnose $\mathrm{MCl}$, and were unable to perform additional examinations such as MRI to improve the accuracy of the diagnosis.

- The small proportion of the population with $\mathrm{MCl}$ at risk of $\mathrm{KOA}$ onset detection might raise a bias in the results of the study.

severe and immediate disabilities. ${ }^{1}$ According to the recent national livelihood survey by the Japanese Ministry of Health, Labour and Welfare, the leading causes of disability requiring support and long-term care were cardiovascular disease (CVD) followed by dementia, cognitive impairment, senility and osteoarthritis (OA). ${ }^{2}$

It is important to establish associations among these diseases causing disability, in order to reduce the risk of disability. In terms of CVD and dementia, the existence of vascular dementia, for example, indicates that there are links between CVD and dementia, and cardiovascular and metabolic risk factors such as hypertension and diabetes may play a role in the pathogenesis of Alzheimer's disease as well as in the development of vascular dementia. ${ }^{3-6}$ Association between metabolic syndrome and risk of developing cognitive impairment has been demonstrated in older women, with a $23 \%$ age-adjusted increase in the risk of developing cognitive impairment in the number of components of metabolic syndrome. ${ }^{7}$ Higher total cholesterol and low-density lipoprotein, and history of diabetes have been associated with faster cognitive decline in patients with incident Alzheimer's disease. $^{8}$

However, as per our knowledge, there have been no previous reports on the association between $\mathrm{OA}$ and dementia. Mild cognitive impairment (MCI), a transitional state associated with memory impairment, has been associated with an increased risk of progression of Alzheimer's disease. ${ }^{9}{ }^{10}$ We aimed to investigate the association between MCI and the occurrence and progression of radiographic knee osteoarthritis (KOA) among men and women who participated in the Research on Osteoarthritis/Osteoporosis Against Disability (ROAD) study.

\section{PARTICIPANTS AND METHODS}

\section{Participants}

Our analysis was based on data collected from cohorts established in 2005 for the ROAD study. Details of the cohort have been reported elsewhere. ${ }^{11}{ }^{12}$ In brief, we created a baseline database in 2005-2007, which included clinical and genetic information for 3040 residents of Japan (1061 men, 1979 women). Participants were recruited from resident registration listings in three communities, each with different characteristics, namely an urban region in Itabashi, Tokyo; a mountainous region in Hidakagawa, Wakayama; and a coastal region in Taiji, Wakayama.

For the present study, we enrolled 1690 participants (596 men, 1094 women) residing in the mountainous and coastal areas, where the mental test was performed at baseline. Participants provided written informed consent, and the study was conducted with the approval of the ethics committees of the University of Tokyo (approval number 1264).

\section{Baseline procedures}

Participants completed an interviewer-administered questionnaire comprising 400 items. These included lifestyle-related questions to obtain information about main occupation; smoking habits (0: exsmoker or never smoked, 1: current smoker); alcohol consumption (0: exdrinker or never drank, 1: current drinker); alcohol consumption; physical activity including cycling every day in the past 12 months (0: no, 1: yes); regular exercise, that is, football, tennis, baseball, golf or other sports after graduation from school (0: no, 1: yes); and medical history including history of knee injury (0: no, 1 : yes).

Anthropometric measurements included height, weight, body mass index (BMI) calculated as weight $(\mathrm{kg}) /$ height $\left(\mathrm{m}^{2}\right)$ and grip strength of both hands. Experienced orthopaedic surgeons (SM and $\mathrm{HO}$ ) collected medical information about pain, swelling and the range of motion in the knee.

All participants underwent a radiographic examination of both knees using an anteroposterior view with weight-bearing and foot map positioning. Fluoroscopic guidance with a horizontal anteroposterior x-ray beam was used to properly visualise the joint space.

Cognitive functioning was measured using the minimental state examination (MMSE). ${ }^{13}$ This is a 30 -item cognitive screening test that measures orientation, registration, short-term memory, attention and concentration, language and constructional capacity. The testretest reliability of the original version of the MMSE is $0.83,{ }^{13}$ and the criterion validity is $0.66-0.79$ with the Wechsler Adult Intelligence Scale, 0.83 with the Short Portable Mental Status Questionnaire and 0.88 with the Cognitive Capacity Screening Examination. ${ }^{14} 15$ We used the validated Japanese version of the MMSE. ${ }^{16}$ Summary scores from the MMSE were used to measure cognitive 
functioning and the criterion for MCI was a summary score $\leq 23$.

\section{Three-year follow-up and definition of the occurrence} and progression of radiographic Knee osteoarthritis

In 2008-2010, the 1690 participants were invited to attend the 3-year follow-up of the second ROAD survey, which involved a repeat of the baseline examinations. Knee radiographs obtained at baseline and follow-up were read in pairs without knowledge of the participant's clinical status by a single well-experienced orthopaedist $(\mathrm{SM})$, and the Kellgren/Lawrence $(\mathrm{K} / \mathrm{L})$ grade was defined using the $\mathrm{K} / \mathrm{L}$ radiographic atlas for overall knee radiographic grades. ${ }^{17}$ To evaluate the intraobserver variability of the $\mathrm{K} / \mathrm{L}$ grading, 100 randomly selected radiographs of the knee were scored by the same observer 1 month after the first reading. One hundred other radiographs were also scored by two experienced orthopaedic surgeons ( $\mathrm{SM}$ and $\mathrm{HO}$ ) using the same atlas for interobserver variability. The intravariabilities and intervariabilities evaluated for $\mathrm{K} / \mathrm{L}$ grade $(0-4)$ were confirmed by kappa analysis to be sufficient for assessment $(\kappa=0.86$ and 0.80 , respectively). When a different grade was assigned to each knee, the participant was classified by the higher grade. A participant with a KL grade $\geq 2$ was defined as having radiographic KOA. A new case of radiographic KOA was identified if the KL grade at baseline had been $<2$ for both knees, and if one or both knees were assigned grade $\geq 2$ at follow-up. A higher KL grade for either knee at follow-up compared with the baseline was defined as progression of OA.

\section{Statistical analysis}

Statistical analyses were performed using STATA statistical software (STATA Corp, College Station, Texas, USA). Differences in proportions were compared using the $\chi^{2}$ test. Differences in continuous variables were tested for significance using analysis of variance (ANOVA) for multiple groups or Scheffé's least significant difference test for pairs of groups. To test the association between occurrence or progression of radiographic KOA and the presence of MCI after adjustment for confounding factors, we performed two types of multivariate logistic regression analysis. For both, we entered the occurrence or progression of $\mathrm{OA}$ over 3 years (1: yes, $0:$ no) as the dependent variable, and the MMSE summary score or presence of MCI (1: presence, 0 : absence) as the independent variable. In model 1 , the analysis was performed after adjusting for age, gender, regional differences and BMI. In model 2, we adjusted for potential risk factors that had previously been identified in this cohort as significantly associated with the presence of $\mathrm{KOA},{ }^{9} 18$ namely age, gender, regional differences, BMI, grip strength $(\mathrm{kg})$ on the worse side, smoking, alcohol consumption, regular exercise and history of knee injuries. All p values and 95\% CI of twosided analysis are presented.

\section{RESULTS}

Eligible participants

Of the all 1690 participants in the baseline survey performed in the mountainous and coastal regions, 251 individuals (14.9\%; 104 men, 147 women) did not attend the 3-year follow-up. Among them, 40 (27 men, 13 women) had died, 97 (32 men, 65 women) did not attend follow-up due to bad health, 16 (5 men, 11 women) had moved away, 51 (24 men, 27 women) declined the invitation to attend the second survey, 8 (4 men, 4 women) were absent and 39 (12 men, 27 women) did not participate for other reasons. In addition, 55 participants in the second survey (3.3\%; 26 men, 29 women) did not complete all the follow-up examinations, including the interviewer-administered questionnaire, anthropometric measurements, radiographic examination and blood tests. Thus, our analysis was based on the remaining 1384 subjects (81.9\%; 466 men, 918 women) who completed all examinations at both the baseline and follow-up (figure 1).

\section{Prevalence of $\mathrm{MCl}$ and its baseline characteristics}

The prevalence of MCI and baseline characteristics of the 1384 participants are shown in table 1 . Based on the MMSE summary score, 75 participants (30 men, 45 women) were diagnosed with MCI (prevalence, $4.5 \%$; men, $5.1 \%$, women, $4.2 \%$ ). The prevalence of MCI was significantly higher in the older age groups (trend, $\mathrm{p}<0.001)$. The mean MMSE summary score was significantly lower in participants with MCI than in those without (21.2 vs 28.5). Participants with MCI tended to reside in mountainous areas, and they had significantly lower weight, height and grip strength; drank less alcohol and exercised less compared with those without MCI (table 1). In addition, the prevalence of radiographic KOA classified by presence of MCI was compared in table 1 . In total, $75.7 \%$ of patients in the MCI group were observed to have KOA, which was

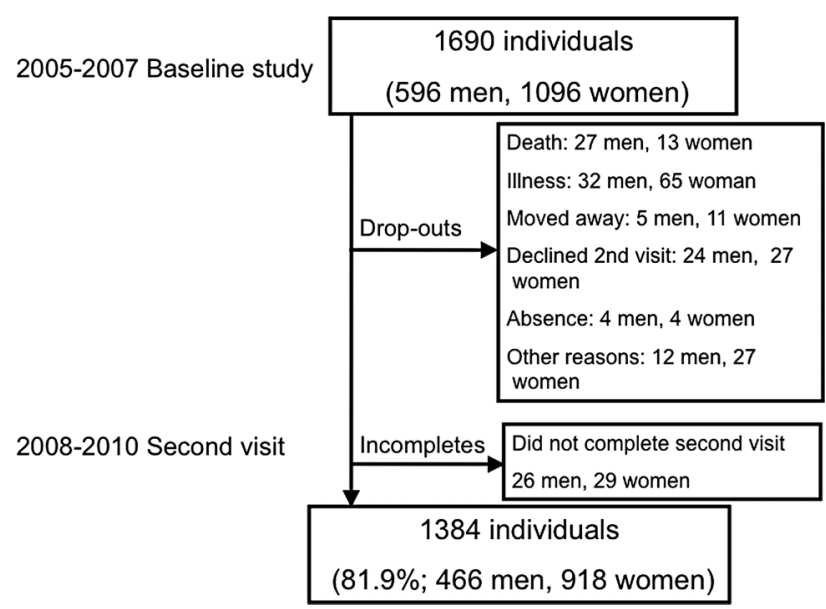

Figure 1 Flow diagram for participation in the baseline and follow-up Research on Osteoarthritis/osteoporosis Against Disability surveys. 
Table 1 Comparison of baseline characteristics of subjects without and with mild cognitive impairment (MCl)

\begin{tabular}{|c|c|c|c|c|c|c|c|c|c|}
\hline & \multicolumn{3}{|c|}{ Total $(n=1676)$} & \multicolumn{3}{|l|}{ Men $(n=591)$} & \multicolumn{3}{|c|}{ Women $(n=1085)$} \\
\hline & Without $\mathrm{MCl}$ & With $\mathrm{MCl}$ & p Value & $\begin{array}{l}\text { Without } \\
\mathrm{MCl}\end{array}$ & With MCI & p Value & Without $\mathrm{MCl}$ & With $\mathrm{MCl}$ & p Value \\
\hline & $(\mathrm{N}=1601)$ & $(\mathrm{N}=75)$ & $\begin{array}{l}\text { (Without vs } \\
\text { with } \mathrm{MCl} \text { ) }\end{array}$ & $(\mathrm{N}=561)$ & $(\mathrm{N}=30)$ & $\begin{array}{l}\text { (Without vs } \\
\text { with } \mathrm{MCl} \text { ) }\end{array}$ & $(\mathrm{N}=1040)$ & $(\mathrm{N}=45)$ & $\begin{array}{l}\text { (Without vs } \\
\text { with } \mathrm{MCl} \text { ) }\end{array}$ \\
\hline \multicolumn{10}{|c|}{ Number of subjects (prevalence, \%) classified by age-strata } \\
\hline$\leq 39$ (year) & 45 & $0(0.0)$ & & 14 & $0(0.0)$ & & 31 & $0(0.0)$ & \\
\hline 40-49 & 148 & $1(0.7)$ & & 43 & $1(2.3)$ & & 105 & $0(0.0)$ & \\
\hline $50-59$ & 314 & $2(0.6)$ & $<0.001^{\star \star *}$ & 106 & $1(0.9)$ & $<0.001^{* * *}$ & 208 & $1(0.5)$ & $<0.001^{\star \star *}$ \\
\hline $60-69$ & 467 & $10(2.1)$ & & 151 & $5(3.2)$ & & 316 & $5(1.6)$ & \\
\hline 70-79 & 496 & $35(6.6)$ & & 202 & $14(6.5)$ & & 294 & $21(6.7)$ & \\
\hline$\geq 80$ & 131 & $27(17.1)$ & & 45 & $9(16.7)$ & & 86 & $18(17.3)$ & \\
\hline $\bar{T}$ Total & 1601 & $75(4.5)$ & & 561 & $30(5.1)$ & & 1040 & $45(4.2)$ & \\
\hline $\begin{array}{l}\text { Mean values (SDs) of } \\
\text { MMSE summary score }\end{array}$ & $28.5(1.7)$ & $21.2(3.2)$ & $<0.0001^{\star * *}$ & $28.4(1.8)$ & $20.7(4.4)$ & $<0.0001^{* * *}$ & $28.6(1.7)$ & $21.5(2.1)$ & $<0.0001^{\star * \star}$ \\
\hline \multicolumn{10}{|c|}{ Mean values (SDs) of selected characteristics } \\
\hline Age (year) & $64.7(11.9)$ & $75.8(8.1)$ & $<0.0001^{\star \star \star}$ & $65.8(11.7)$ & $74.0(9.3)$ & $0.0002^{\star \star \star}$ & $64.1(12.0)$ & $77.0(6.9)$ & $<0.0001^{\star \star \star}$ \\
\hline Height $(\mathrm{cm})$ & $155.5(9.1)$ & $148.7(9.8)$ & $<0.0001^{\star \star \star}$ & $163.8(7.1)$ & $157.4(5.8)$ & $<0.0001^{\star \star *}$ & $151.1(6.7)$ & $142.9(7.4)$ & $<0.0001^{\star \star \star}$ \\
\hline Weight (kg) & $55.8(10.7)$ & $51.7(11.7)$ & $0.0011^{\star *}$ & $62.5(10.8)$ & $57.7(12.1)$ & $0.0181^{*}$ & $52.2(8.8)$ & $47.7(9.6)$ & $0.0007^{\star \star \star}$ \\
\hline BMI $\left(\mathrm{kg} / \mathrm{m}^{2}\right)$ & $23.0(3.4)$ & $23.2(3.7)$ & 0.5845 & $23.2(3.2)$ & $23.2(3.9)$ & 0.9346 & $22.9(3.5)$ & 23.2 & 0.4877 \\
\hline $\begin{array}{l}\text { Grip strength } \\
\text { (better side) (kg) }\end{array}$ & $27.8(9.5)$ & $20.8(8.5)$ & $<0.0001^{\star * *}$ & $36.4(8.8)$ & $27.6(8.2)$ & $<0.0001^{\star * *}$ & $23.3(6.0)$ & $16.5(5.3)$ & $<0.0001^{\star * \star}$ \\
\hline $\begin{array}{l}\text { Grip strength } \\
\text { (worse side) }(\mathrm{kg})\end{array}$ & $24.6(9.3)$ & $16.8(9.3)$ & $<0.0001^{\star * *}$ & $32.8(9.1)$ & $22.4(10.6)$ & $<0.0001^{\star \star \star}$ & $20.1(5.6)$ & $13.1(6.2)$ & $<0.0001^{\star \star \star}$ \\
\hline \multicolumn{10}{|c|}{ Percentage of selected characteristics (\%) } \\
\hline Residing in a coastal area & 50.1 & 28.0 & $<0.001^{* * *}$ & 47.8 & 26.7 & $0.024^{*}$ & 51.4 & 28.9 & $0.003^{\star *}$ \\
\hline $\begin{array}{l}\text { Current smoking habit (more } \\
\text { than once a month) }\end{array}$ & 13.3 & 10.0 & 0.428 & 30.4 & 21.4 & 0.312 & 3.9 & 2.4 & 0.624 \\
\hline $\begin{array}{l}\text { Current alcohol } \\
\text { consumption (more than } \\
\text { once a month) }\end{array}$ & 40.5 & 24.0 & $0.004^{\star *}$ & 67.6 & 46.7 & $0.018^{\star}$ & 26.0 & 8.9 & $0.010^{*}$ \\
\hline $\begin{array}{l}\text { Regular exercise after } \\
\text { graduation from school }\end{array}$ & 14.9 & 4.0 & $0.008^{\star *}$ & 34.4 & 6.7 & $0.002^{\star \star}$ & 4.4 & 2.2 & 0.478 \\
\hline $\begin{array}{l}\text { Prevalence of KOA at the } \\
\text { baseline (\%) }\end{array}$ & 48.8 & 75.7 & $<0.001^{\star \star \star}$ & 41.0 & 50.0 & 0.328 & 53.0 & 93.2 & $<0.001^{\star \star *}$ \\
\hline
\end{tabular}


significantly higher than the percentage in the without-MCI group $(48.8 \%, \mathrm{p}<0.001)$. This significant tendency was observed in women, while in men the association was not significant.

\section{Occurrence of radiographic KOA in participants with and without MCI}

The baseline prevalence of KOA in the 1384 individuals who attended follow-up was $46.8 \%$ (men $37.3 \%$; women $51.6 \%)$. After the exclusion of participants with a baseline $\mathrm{KL}$ grade $\geq 2$ at one or both knees, the cumulative incidence of OA during the 3-year follow-up period was estimated using an at-risk population of 728 individuals (290 men, 438 women) without OA in either knee at baseline. Among these, 71 participants (18 men, 53 women) were newly diagnosed with $\mathrm{KOA}$, and the annual cumulative incidence was estimated as 3.3\% (men 2.1\%; women 4.0\%). The incidence of KOA increased with age (table 2).

The MMSE score was significantly lower in participants with, compared to those without, incident radiographic KOA $(p<0.0001)$, and the prevalence of MCI at baseline was significantly higher $(p=0.003)$. Those with KOA tended to reside in a mountainous area, were significantly taller, had greater BMI and weaker grip strength in both hands and were less likely to smoke, drink alcohol or exercise regularly compared with those without OA. History of knee injury was more common among those without KOA (table 2).

On univariate regression analysis, a one-digit increase in the MMSE score was associated with a $24 \%$ decreased risk of incident radiographic KOA ( $<<0.001$; table 3$)$. This trend remained after adjustment for age, gender, regional differences and BMI in model 1 (OR 0.85 for +1 MMSE score; $\mathrm{p}=0.015$ ) and after adjustment for age, gender, regional differences, BMI, grip strength $(\mathrm{kg})$ on the worse side, smoking, alcohol consumption, regular exercise and history of knee injury in model 2 (OR 0.83 ; $\mathrm{p}=0.010)$. The presence of MCI was associated with a fivefold increased risk of incident KOA $(p=0.008)$, with ORs of $4.59(\mathrm{p}=0.027)$ in model 1 and $4.90(\mathrm{p}=0.027)$ in model 2.

\section{Progression of radiographic KOA with and without $\mathrm{MCI}$}

We excluded 88 participants (21 men, 67 women) with a baseline KL grade of 4 at one or both knees, before estimating the cumulative rate for the progression of KOA during a 3-year follow-up. We estimated the rate of progression rate in KL grades over the 3 years using the population at risk comprising 1296 individuals (445 men, 851 women). Among these, 311 individuals (86 men, 225 women) had a higher KL grade assigned to one or both knees at follow-up than at baseline. The annual rate of progression in KL grades for either knee over the 3-year period was $8.0 \%$ (men $6.4 \%$, women $8.8 \%$ ) in the overall population at risk, and the rate increased with age (table 4). The MMSE summary score was significantly lower $(p<0.0001)$ and the baseline prevalence of MCI was significantly higher $(p=0.008)$ in participants with, than in those without, progression of radiographic KOA. Participants with progression of radiographic KOA tended to reside in a mountainous area, were significantly older and taller, had greater BMI and weaker grip strength in both hands and were less likely to smoke, drink alcohol or take regular exercise compared to those who did not have progression of KOA (table 4).

A one-digit increase in the MMSE was associated with a $16 \%$ increased risk of progression of radiographic KOA (OR 0.84; $\mathrm{p}<0.001$ ). This tendency was no longer significant after adjustment for age, gender, regional differences and BMI in model 1 (OR 0.95; $\mathrm{p}=0.131$ ), and for age, gender, regional differences, BMI, grip strength (worst side), smoking, alcohol consumption, regular exercise and history of knee injuries in model 2 (OR $0.96 ; \mathrm{p}=0.232$; table 5 ). On univariate analysis, the presence of MCI was associated with a 2.5-fold increased risk of progression of KOA (OR 2.54; $\mathrm{p}=0.010$ ), but this was not significant after adjustment for confounding factors in model 1 (OR 1.56; $\mathrm{p}=0.242$ ) or model 2 (OR 1.38; $\mathrm{p}=0.416$ ).

\section{Association of inflammation and metabolic risk factors with both $\mathrm{KOA}$ and $\mathrm{MCI}$}

In addition to the factors adjusted in model 2, we assessed the following two factors as potential confounders influencing both KOA and MCI: subclinical inflammation and metabolic risk factors.

As an index of inflammation, baseline serum $\mathrm{C}$ reactive protein (CRP) level was added as an explanatory factor in a logistic regression analysis similar to that performed in model 2. The adjusted ORs for the occurrence of $\mathrm{OA}$ in relation to the MMSE summary score (OR 0.83 ; $95 \%$ CI, 0.72 to 0.96 for +1 MMSE score; $\mathrm{p}=0.010)$ or to the presence of MCI (OR 5.18; 95\% CI, 1.24 to 21.6 for presence of $\mathrm{MCI} ; \mathrm{p}=0.024$ ) remained unchanged, and the serum CRP level was not significantly associated with occurrence (OR $0.47 ; 95 \% \mathrm{CI}$, 0.09 to 2.40 for +1 CRP level; $\mathrm{p}=0.365$ ) or progression of OA (OR 0.96; 95\% CI, 0.67 to $1.37 ; \mathrm{p}=0.818$ ).

Then, we performed logistic regression analysis, similar to that performed in model 2 , by using the metabolic risk factors overweight (1: BMI $\geq 25 \mathrm{~kg} / \mathrm{m}^{2}$, 0 : $\mathrm{BMI}<25 \mathrm{~kg} / \mathrm{m}^{2}$ ), hypertension (1: systolic blood pressure (BP) $\geq 130 \mathrm{~mm} \mathrm{Hg}$ and/or diastolic BP $\geq 85 \mathrm{~mm} \mathrm{Hg}, 0$ : systolic BP $<130 \mathrm{~mm} \mathrm{Hg}$ and diastolic BP $<84 \mathrm{~mm} \mathrm{Hg}$ ), dyslipidaemia (1: serum high-density lipoprotein cholesterol (HDL-cho) level $<40 \mathrm{mg} / \mathrm{dl}$, 0: HDL-cho level $\geq 40 \mathrm{mg} / \mathrm{dl}$ ) and impaired glucose tolerance (1: serum haemoglobin A1c (HbA1c) level $\geq 5.5 \%$, 0 : HbA1c level $<5.5 \%)$. Furthermore, subjects receiving medication for hypertension, dyslipidaemia or diabetes mellitus were regarded as having hypertension, dyslipidaemia or impaired glucose tolerance, respectively. The adjusted ORs for the occurrence of KOA in relation to the MMSE summary score (OR 0.84; $95 \%$ CI, 0.73 to 
Table 2 Mean values (SDs) of anthropometric factors, mini-mental state examination (MMSE) and prevalence of mild cognitive impairment (MCl) and selected characteristics vs the occurrence of knee osteoarthritis

\begin{tabular}{|c|c|c|c|c|c|c|c|c|c|}
\hline & \multirow[b]{2}{*}{$\begin{array}{l}\text { KOA (-) } \\
(n=657)\end{array}$} & \multicolumn{3}{|l|}{ Total } & \multicolumn{3}{|l|}{ Men } & \multicolumn{2}{|l|}{ Women } \\
\hline & & $\begin{array}{l}\text { KOA (+) } \\
(n=71)\end{array}$ & p Value & $\begin{array}{l}\text { KOA (-) } \\
(n=272)\end{array}$ & $\begin{array}{l}\text { KOA (+) } \\
(n=18)\end{array}$ & p Value & $\begin{array}{l}\text { KOA (-) } \\
(n=385)\end{array}$ & $\begin{array}{l}\text { KOA (+) } \\
(n=53)\end{array}$ & p Value \\
\hline \multicolumn{10}{|c|}{ Number of subjects classified by age-strata (cumulative incidence, \%/year) } \\
\hline$\leq 39$ (year) & 38 & $0(0.0)$ & & 10 & $0(0.0)$ & & 28 & $0(0.0)$ & \\
\hline 40-49 & 118 & $1(0.3)$ & & 36 & $0(0.0)$ & & 82 & $1(0.4)$ & \\
\hline $50-59$ & 201 & $15(2.3)$ & $<0.001^{\star \star *}$ & 77 & $0(0.0)$ & $0.009^{\star *}$ & 124 & (3.6) & $<0.001^{\star \star \star}$ \\
\hline $60-69$ & 177 & $27(4.4)$ & & 76 & $11(4.2)$ & & 101 & (4.6) & \\
\hline 70-79 & 108 & $23(5.9)$ & & 62 & $6(2.9)$ & & 46 & $17(9.0)$ & \\
\hline$\geq 80$ & 15 & $5(8.3)$ & & 11 & $1(2.8)$ & & 4 & $4(16.7)$ & \\
\hline \multicolumn{10}{|c|}{ Mean values (SDs) for MMSE summary score and prevalence of $\mathrm{MCl}$} \\
\hline MMSE summary score & $29.1(1.6)$ & $28.0(2.3)$ & $<0.0001^{\star \star \star}$ & $28.8(1.9)$ & $27.3(2.7)$ & $0.0017^{* *}$ & $29.3(1.3)$ & $28.2(2.1)$ & $<0.0001^{\star \star \star}$ \\
\hline Prevalence of $\mathrm{MCl}(\%)$ & $7 / 654(1.1)$ & $4 / 71(5.6)$ & $0.003^{\star *}$ & $6 / 270(2.2)$ & $2 / 18(11.1)$ & $0.026^{\star}$ & $1 / 384(0.3)$ & $2 / 53(3.8)$ & $0.004^{*}$ \\
\hline \multicolumn{10}{|c|}{ Mean values (SDs) for age, anthropometric factors and neuromuscular function } \\
\hline Age (year) & $58.2(11.8)$ & $67.3(8.2)$ & $<0.0001^{\star \star \star}$ & $61.0(11.8)$ & $70.0(6.1)$ & $0.0021^{\star *}$ & $56.4(11.4)$ & $66.4(8.7)$ & $<0.0001^{\star \star \star}$ \\
\hline Height (cm) & $158.8(8.6)$ & $153.9(7.6)$ & $<0.0001^{\star \star \star}$ & $165.6(7.0)$ & $162.0(5.0)$ & $0.0360^{*}$ & $154.0(6.0)$ & $151.2(6.2)$ & $0.0018^{\star \star}$ \\
\hline Weight (kg) & $56.8(11.0)$ & $56.0(8.8)$ & 0.5560 & $63.7(11.0)$ & $63.7(9.2)$ & 0.9859 & $51.9(8.1)$ & $53.4(7.1)$ & 0.2051 \\
\hline BMI $\left(\mathrm{kg} / \mathrm{m}^{2}\right)$ & $22.4(3.2)$ & $23.6(2.9)$ & $0.0035^{\star *}$ & $23.2(3.2)$ & $24.2(3.1)$ & 0.1709 & $21.9(3.1)$ & $23.4(2.8)$ & $0.0012^{* *}$ \\
\hline Grip strength (better side) (kg) & $31.3(9.9)$ & $26.7(8.1)$ & $0.0002^{\star \star \star}$ & $39.4(8.8)$ & $35.9(7.1)$ & 0.0996 & $25.6(6.0)$ & $23.5(5.6)$ & $0.0171^{*}$ \\
\hline Grip strength (worse side) (kg) & $28.0(9.6)$ & $23.0(8.5)$ & $<0.0001^{\star \star \star}$ & $35.9(9.0)$ & $30.7(11.0)$ & $0.0188^{*}$ & $22.5(5.1)$ & $20.4(5.5)$ & $0.0065^{\star *}$ \\
\hline \multicolumn{10}{|l|}{ Percentage of selected characteristics, $\%$} \\
\hline Residing in a coastal area & 70.8 & 56.3 & $0.012^{*}$ & 66.9 & 55.6 & 0.324 & 73.5 & 56.6 & $0.011^{*}$ \\
\hline Current smoking habit (more than once a month) & 16.9 & 7.1 & $0.034^{*}$ & 34.2 & 27.8 & 0.577 & 4.7 & 0.0 & 0.110 \\
\hline $\begin{array}{l}\text { Current alcohol consumption (more than once a } \\
\text { month) }\end{array}$ & 47.9 & 35.2 & $0.041^{*}$ & 70.0 & 61.1 & 0.428 & 32.5 & 26.4 & 0.375 \\
\hline Regular exercise after graduation from school & 19.9 & 7.0 & $0.008^{\star *}$ & 37.5 & 27.8 & 0.408 & 7.5 & 0.0 & $0.039^{*}$ \\
\hline Past injury of either knee & 1.8 & 5.6 & $0.038^{*}$ & 0.4 & 5.6 & $0.010^{*}$ & 2.9 & 5.7 & 0.277 \\
\hline
\end{tabular}

${ }^{*} \mathrm{p}<0.05,{ }^{* *} \mathrm{p}<0.01,{ }^{* * *} \mathrm{p}<0.001$

$\mathrm{BMI}$, body mass index; KOA, knee osteoarthritis; KOA(-), non-occurrence of KOA; KOA(+), occurrence of KOA; n, number of subjects. 
Table 3 ORs for occurrence of knee osteoarthritis during the 3-year follow-up period versus mild cognitive impairment (MCl)

\begin{tabular}{|c|c|c|c|c|c|c|c|c|c|c|}
\hline \multicolumn{2}{|l|}{ MMSE summary score } & \multicolumn{3}{|c|}{ Univariate analysis } & \multicolumn{3}{|c|}{ Logistic regression model 1} & \multicolumn{3}{|c|}{ Logistic regression model 2} \\
\hline Explanatory variables & Reference & $\overline{\text { OR }}$ & $95 \% \mathrm{Cl}$ & p Value & $\overline{\text { OR }}$ & $95 \% \mathrm{Cl}$ & p Value & $\overline{\text { OR }}$ & $95 \% \mathrm{Cl}$ & p Value \\
\hline $\begin{array}{l}\text { MMSE summary score } \\
\text { Other potential risk actors }\end{array}$ & +1 score & 0.76 & 0.68 to 0.85 & $<0.001^{\star \star \star}$ & 0.85 & 0.73 to 0.97 & $0.015^{\star}$ & 0.83 & 0.72 to 0.96 & $0.010^{*}$ \\
\hline Age (year) & 1 year & & & & 1.09 & 1.06 to 1.13 & $<0.001^{* *}$ & 1.10 & 1.06 to 1.14 & $<0.001^{\star \star \star}$ \\
\hline Gender & $0:$ men, $1:$ women & & & & 4.36 & 2.33 to 8.16 & $<0.001^{\star \star}$ & 4.02 & 1.50 to 10.74 & $0.006^{\star \star}$ \\
\hline Region & $\begin{array}{l}\text { 0: mountainous area, } \\
\text { 1: coastal area }\end{array}$ & & & & 0.78 & 0.45 to 1.35 & 0.380 & 0.76 & 0.43 to 1.35 & 0.354 \\
\hline BMI $\left(\mathrm{kg} / \mathrm{m}^{2}\right)$ & $+1 \mathrm{~kg} / \mathrm{m}^{2}$ & & & & 1.23 & 1.12 to 1.34 & $<0.001^{\star *}$ & 1.22 & 1.11 to 1.34 & $<0.001^{\star \star \star}$ \\
\hline $\begin{array}{l}\text { Grip strength } \\
\text { (worse side) (kg) }\end{array}$ & $+1 \mathrm{~kg}$ & & & & & & & 1.01 & 0.96 to 1.06 & 0.730 \\
\hline Smoking & $\begin{array}{l}0 \text { : exsmoker or never smoker, } \\
\text { 1: current smoker }\end{array}$ & & & & & & & 1.01 & 0.35 to 2.91 & 0.986 \\
\hline Alcohol consumption & $\begin{array}{l}\text { 0: exdrinker or never drinker, } \\
\text { 1: current drinker }\end{array}$ & & & & & & & 1.11 & 0.60 to 2.04 & 0.746 \\
\hline $\begin{array}{l}\text { Regular exercise after } \\
\text { graduation from school }\end{array}$ & $0:$ no, $1:$ yes & & & & & & & 0.57 & 0.20 to 1.65 & 0.302 \\
\hline History of knee injuries & $0:$ no, 1: yes & & & & & & & 4.76 & 1.26 to 17.97 & $0.021^{*}$ \\
\hline $\begin{array}{l}\mathrm{MCl} \\
\text { Explanatory variables }\end{array}$ & & \multicolumn{3}{|c|}{ Univariate analysis } & \multicolumn{3}{|c|}{ Logistic regression model 1} & \multicolumn{3}{|c|}{ Logistic regression model 2} \\
\hline $\begin{array}{l}\mathrm{MCl} \\
\text { Other potential risk actors }\end{array}$ & 0: absence, 1 :presence & 5.52 & 1.57 to 19.34 & $0.008^{\star \star}$ & 4.59 & 1.18 to 17.7 & $0.027^{\star}$ & 4.90 & 1.20 to 20.05 & $0.027^{\star}$ \\
\hline Age (year) & 1 year & & & & 1.10 & 1.07 to 1.14 & $<0.001^{\star *}$ & 1.10 & 1.07 to 1.15 & $<0.001^{\star \star \star}$ \\
\hline Gender & $0:$ men, $1:$ women & & & & 4.36 & 2.32 to 8.17 & $<0.001^{\star \star}$ & 3.80 & 1.42 to 10.19 & $0.008^{\star \star}$ \\
\hline Region & $\begin{array}{l}\text { 0: mountainous area, } \\
\text { 1: coastal area }\end{array}$ & & & & 0.75 & 0.44 to 1.30 & 0.310 & 0.73 & 0.41 to 1.29 & 0.280 \\
\hline BMI $\left(\mathrm{kg} / \mathrm{m}^{2}\right)$ & $+1 \mathrm{~kg} / \mathrm{m}^{2}$ & & & & 1.23 & 1.13 to 1.35 & $<0.001^{\star *}$ & 1.23 & 1.12 to 1.34 & $<0.001^{* * *}$ \\
\hline $\begin{array}{l}\text { Grip strength } \\
\text { (worse side) (kg) }\end{array}$ & $+1 \mathrm{~kg}$ & & & & & & & 1.00 & 0.96 to 1.05 & 0.870 \\
\hline Smoking & $\begin{array}{l}\text { 0: exsmoker or never smoker, } \\
\text { 1: current smoker }\end{array}$ & & & & & & & 1.08 & 0.38 to 3.12 & 0.885 \\
\hline Alcohol consumption & $\begin{array}{l}\text { 0: exdrinker or never drinker, } \\
\text { 1: current drinker }\end{array}$ & & & & & & & 1.10 & 0.59 to 2.02 & 0.770 \\
\hline $\begin{array}{l}\text { Regular exercise after } \\
\text { graduation from school }\end{array}$ & $0:$ no, $1:$ yes & & & & & & & 0.57 & 0.20 to 1.65 & 0.304 \\
\hline $\begin{array}{l}\text { Past history of knee } \\
\text { injuries }\end{array}$ & 0: no, 1: yes & & & & & & & 4.28 & 1.13 to 16.19 & $0.032^{*}$ \\
\hline
\end{tabular}


Table 4 Mean values (SDs) of anthropometric factors, mini-mental state examination (MMSE) and prevalence of mild cognitive impairment (MCI) and selected characteristics versus progression of knee osteoarthritis

\begin{tabular}{|c|c|c|c|c|c|c|c|c|c|}
\hline \multicolumn{10}{|l|}{ Progression of KOA Women } \\
\hline & \multicolumn{3}{|l|}{ Total } & \multicolumn{3}{|l|}{ Men } & \multicolumn{3}{|l|}{ Women } \\
\hline & \multicolumn{2}{|l|}{ Progression } & \multirow[b]{3}{*}{ p Value } & \multicolumn{2}{|l|}{ Progression } & \multirow[b]{3}{*}{ p Value } & \multicolumn{2}{|l|}{ Progression } & \multirow[b]{3}{*}{ p Value } \\
\hline & $(-)$ & $(+)$ & & $(-)$ & $(+)$ & & $(-)$ & $(+)$ & \\
\hline & $(n=985)$ & $(n=311)$ & & $(n=359)$ & $(n=86)$ & & $(n=626)$ & $(n=225)$ & \\
\hline \multicolumn{10}{|c|}{ Number of subjects classified by age-strata (Proportion of progression, \%/year) } \\
\hline$\leq 39$ (year) & 37 & $2(1.7)$ & & 9 & $1(3.3)$ & & 28 & $1(1.1)$ & \\
\hline $40-49$ & 128 & $7(1.7)$ & & 38 & $2(1.7)$ & & 90 & $5(1.8)$ & \\
\hline $50-59$ & 248 & $44(5.0)$ & $<0.001^{\star * *}$ & 89 & $8(2.8)$ & $<0.001^{\star \star \star}$ & 159 & $36(6.2)$ & $<0.001^{\star * \star}$ \\
\hline $60-69$ & 292 & $105(8.2)$ & & 101 & & & 191 & $79(9.8)$ & \\
\hline 70-79 & 241 & $115(10.8)$ & & 105 & $38(8.9)$ & & 136 & $77(12.1)$ & \\
\hline$\geq 80$ & 39 & $38(16.5)$ & & 17 & $11(13.1)$ & & 22 & $27(18.4)$ & \\
\hline \multicolumn{10}{|c|}{ Mean values (SDs) for MMSE summary score and prevalence of $\mathrm{MCl}$} \\
\hline MMSE summary score & $28.7(1.8)$ & $28.0(2.2)$ & $<0.0001^{\star * *}$ & $28.5(1.9)$ & $27.9(2.3)$ & $0.0056^{\star \star}$ & $28.8(1.8)$ & $28.1(2.1)$ & $<0.0001^{\star \star \star}$ \\
\hline Prevalence of $\mathrm{MCl}(\%)$ & $18 / 980(1.8)$ & $14 / 295(4.5)$ & $0.008^{* \star}$ & $9 / 357(2.5)$ & $5 / 85(5.9)$ & 0.112 & $9 / 623(1.4)$ & 9/224 (4.0) & $0.022^{*}$ \\
\hline \multicolumn{10}{|c|}{ Mean values (SDs) for age, anthropometric factors and neuromuscular function } \\
\hline Age (year) & $61.6(11.9)$ & $68.7(9.3)$ & $<0.0001^{* * *}$ & $63.3(11.8)$ & $70.0(9.4)$ & $<0.0001^{* * *}$ & $60.7(11.9)$ & $68.2(9.3)$ & $<0.0001^{\star \star *}$ \\
\hline Height $(\mathrm{cm})$ & $156.7(8.9)$ & $153.1(8.6)$ & $<0.0001^{\star * *}$ & $164.6(7.1)$ & $161.8(6.2)$ & $0.0010^{* *}$ & $152.2(6.4)$ & $149.7(6.9)$ & $<0.0001^{\star * *}$ \\
\hline Weight (kg) & $56.0(10.9)$ & $55.6(9.9)$ & 0.5496 & $63.1(10.9)$ & $62.8(10.2)$ & 0.8520 & $52.0(8.6)$ & $52.9(8.4)$ & 0.1883 \\
\hline $\operatorname{BMI}\left(\mathrm{kg} / \mathrm{m}^{2}\right)$ & 22.7 (3.3) & $23.6(3.1)$ & $<0.0001^{\star * \star}$ & $23.2(3.2)$ & $23.9(3.1)$ & 0.0643 & $22.4(3.3)$ & $23.5(3.1)$ & $<0.0001^{\star \star *}$ \\
\hline Grip strength (better side) (kg) & $29.3(9.7)$ & $25.7(8.0)$ & $<0.0001^{\star \star \star}$ & $38.1(8.7)$ & $34.4(7.2)$ & $0.0003^{\star \star \star}$ & $24.3(6.0)$ & $22.4(5.3)$ & $<0.0001^{\star \star \star}$ \\
\hline Grip strength (worse side) (kg) & $26.0(9.4)$ & $22.5(7.9)$ & $<0.0001^{\star * *}$ & $34.6(8.8)$ & $30.1(8.7)$ & $<0.0001^{\star * *}$ & $21.1(5.3)$ & $19.6(5.2)$ & $0.0003^{\star \star \star}$ \\
\hline \multicolumn{10}{|l|}{ Percentage of selected characteristics (\%) } \\
\hline Residing in a coastal area & 57.9 & 42.1 & $<0.001^{* \star *}$ & 53.8 & 44.2 & 0.110 & 60.4 & 41.3 & $<0.001^{* * *}$ \\
\hline $\begin{array}{l}\text { Current smoking habit (more than once } \\
\text { a month) }\end{array}$ & 14.1 & 8.6 & $0.013^{\star}$ & 31.2 & 24.4 & 0.220 & 4.1 & 2.3 & 0.222 \\
\hline $\begin{array}{l}\text { Current alcohol consumption (more than } \\
\text { once a month) }\end{array}$ & 44.4 & 32.5 & $<0.001^{\star * *}$ & 72.1 & 57.0 & $0.006^{\star *}$ & 28.6 & 23.1 & 0.114 \\
\hline Regular exercise after graduation from school & 18.1 & 8.0 & $<0.001^{\star \star \star}$ & 39.6 & 23.3 & $0.005^{\star *}$ & 5.8 & 2.2 & $0.034^{*}$ \\
\hline Past injury of either knee & 2.0 & 3.2 & 0.226 & 1.1 & 3.5 & 0.112 & 2.6 & 3.1 & 0.660 \\
\hline
\end{tabular}

${ }^{*} \mathrm{p}<0.05$

$\mathrm{KOA}$, knee osteoarthritis; progression(-), no progression of the Kellgren-Lawrence grade; progression(+), progression of the Kellgren-Lawrence grade. $\mathrm{BMI}$, body mass index; $n$, number of subjects. 
Table 5 OR for the progression of the Kellgren-Lawrence grade for either knee during the 3-year follow-up period versus mild cognitive impairment (MCl)

\begin{tabular}{|c|c|c|c|c|c|c|c|c|c|c|}
\hline \multicolumn{3}{|l|}{ MMSE summary score } & \multicolumn{2}{|c|}{ Univariate analysis } & \multicolumn{3}{|c|}{ Logistic regression model 1} & \multicolumn{3}{|c|}{ Logistic regression model 2} \\
\hline Explanatory variables & Reference & OR & $95 \% \mathrm{Cl}$ & $\begin{array}{l}\mathbf{p} \\
\text { Value }\end{array}$ & OR & $95 \% \mathrm{Cl}$ & p Value & OR & $95 \% \mathrm{Cl}$ & p Value \\
\hline $\begin{array}{l}\text { MMSE summary score } \\
\text { Other potential risk actors }\end{array}$ & +1 score & 0.84 & 0.79 to $0.90<$ & $.001^{* \star *}$ & 0.95 & 0.88 to 1.02 & 0.131 & 0.96 & 0.89 to 1.03 & 0.232 \\
\hline Gender & $0:$ men, 1 : women & & & & 1.89 & 1.40 to 2.55 & $<0.001^{\star \star \star}$ & 1.29 & 0.798 to 2.11 & 0.308 \\
\hline Region & $\begin{array}{l}\text { 0: mountainous area, coastal } \\
\text { 1: area }\end{array}$ & & & & 0.75 & 0.57 to 1.00 & $0.048^{*}$ & 0.69 & 0.52 to 0.92 & $0.011^{*}$ \\
\hline BMI $\left(\mathrm{kg} / \mathrm{m}^{2}\right)$ & $+1 \mathrm{~kg} / \mathrm{m}^{2}$ & & & & 1.12 & 1.07 to 1.17 & $<0.001^{\star \star \star}$ & 1.13 & 1.08 to 1.18 & $<0.001^{\star \star \star}$ \\
\hline Smoking & $\begin{array}{l}\text { 0: exsmoker or never smoker, } \\
\text { 1: current smoker }\end{array}$ & & & & & & & 0.99 & 0.59 to 1.64 & 0.964 \\
\hline Alcohol consumption & $\begin{array}{l}0: \text { exdrinker or never drinker, } \\
1 \text { current drinker }\end{array}$ & & & & & & & 0.84 & 0.61 to 1.15 & 0.274 \\
\hline $\begin{array}{l}\text { Regular exercise after } \\
\text { graduation from school }\end{array}$ & $0:$ no, $1:$ yes & & & & & & & 0.55 & 0.33 to 0.91 & $0.021^{*}$ \\
\hline History of knee injuries & $0:$ no, 1: yes & & & & & & & 2.27 & 0.99 to 5.22 & 0.053 \\
\hline Other potential risk actors & & & & & & & & & & \\
\hline Age (year) & +1 year & & & & 1.07 & 1.05 to 1.08 & $<0.001^{* * *}$ & 1.06 & 1.04 to 1.08 & $<0.001^{* * *}$ \\
\hline Gender & $0:$ men, 1 : women & & & & 1.89 & 1.40 to 2.54 & $<0.001^{* * *}$ & 1.26 & 0.77 to 2.05 & 0.353 \\
\hline Region & $\begin{array}{l}\text { 0: mountainous area, coastal } \\
\text { 1: area }\end{array}$ & & & & 0.75 & 0.56 to 0.99 & $0.041^{*}$ & 0.68 & 0.51 to 0.91 & $0.010^{\star}$ \\
\hline BMI $\left(\mathrm{kg} / \mathrm{m}^{2}\right)$ & $+1 \mathrm{~kg} / \mathrm{m}^{2}$ & & & & 1.13 & 1.08 to 1.17 & $<0.001^{* * *}$ & 1.13 & 1.08 to 1.18 & $<0.001^{* * *}$ \\
\hline $\begin{array}{l}\text { Grip strength } \\
\text { (worse side) (kg) }\end{array}$ & $+1 \mathrm{~kg}$ & & & & & & & 0.99 & 0.97 to 1.02 & 0.484 \\
\hline Smoking & $\begin{array}{l}\text { 0: exsmoker or never smoker, } \\
\text { 1: current smoker }\end{array}$ & & & & & & & 0.99 & 0.60 to 1.65 & 0.974 \\
\hline Alcohol consumption & $\begin{array}{l}\text { 0: exdrinker or never drinker, } \\
\text { 1: current drinker }\end{array}$ & & & & & & & 0.83 & 0.61 to 1.15 & 0.264 \\
\hline $\begin{array}{l}\text { Regular exercise after } \\
\text { graduation from school }\end{array}$ & $0:$ no, $1:$ yes & & & & & & & 0.55 & 0.33 to 0.91 & $0.021^{*}$ \\
\hline History of knee injuries & $0:$ no, 1: yes & & & & & & & 2.27 & 0.99 to 5.21 & 0.053 \\
\hline
\end{tabular}


0.97 for +1 MMSE score; $\mathrm{p}=0.019)$ or to the presence of MCI (OR 4.78; 95\% CI, 1.15 to 19.9 for the presence of MCI; $p=0.032$ ) remained significant, and hypertension was also significantly associated with the occurrence of KOA in relation to MMSE summary score (OR 2.23; $95 \%$ CI, 1.04 to 4.79 for the presence of hypertension; $\mathrm{p}=0.039$ ) or to the presence of MCI (OR 2.26; 95\% CI, 1.06 to $4.85 ; \mathrm{p}=0.036$ ). However, there was no significant association between the occurrence of $\mathrm{KOA}$ and overweight, dyslipidaemia and impaired glucose tolerance after adjustment for the factors used in model 2.

\section{DISCUSSION}

We studied a population-based cohort with a high participation rate $(81.9 \%)$ over a period of 3 years, and observed a significant association between the baseline presence of MCI and incident radiographic KOA identified at 3-year follow-up. This association persisted after adjustment for potential confounding factors.

In contrast, we did not observe an association between MCI and further progression of radiographic KOA identified at baseline. We identified progression of $\mathrm{KOA}$ when the KL grade was higher at follow-up than at baseline; MCI might have had less influence in patients with an increase of at least one KL grade compared to baseline. We reanalysed the influence of the MMSE score or the presence of MCI on rapid progression of OA, which was defined as an increase of at least two KL grades at either knee at follow-up. The results were similar after adjustment for confounders as in model 2; that is, we identified a significant association between MMSE score and rapid progression of OA (OR 0.84; 95\% CI, 0.73 to 0.98 , for +1 MMSE score; $p=0.026)$. The $O R$ for rapid progression of $\mathrm{OA}$ was increased in the presence of MCI, but not significantly so (OR 2.73; $95 \%$ CI, 0.71 to $10.5 ; \mathrm{p}=0.144)$. Then we concluded that the influence of cognitive decline in the future KOA was more pronounced in occurrence of radiographic KOA than in progression.

Links between musculoskeletal disease and dementia have been reported previously; osteoporosis at the femoral neck, for example, is more common in patients with Alzheimer's disease than in healthy volunteers, ${ }^{19}$ but the relationship between KOA and dementia has not been examined. In the current analysis, we showed that the occurrence of KOA was influenced not only by the MMSE scores but also by the presence of MCI. We think that this may be the effect of subclinical inflammation in both MCI and KOA, as inflammatory mechanisms could be involved in the pathogenesis of MCI ${ }^{19}{ }^{20}$ as well as OA. ${ }^{21}$ Therefore, we performed logistic regression analysis similar to that performed in model 2, with the addition of the CRP values. The adjusted ORs for the occurrence of OA in relation to the MMSE summary score or to the presence of MCI remained unchanged, and serum CRP level was not significantly associated with occurrence or progression of OA. However, we used a standard method to measure CRP levels, and further studies using a more sensitive measurement method are required to assess the effect of systemic inflammation on cognitive impairment and KOA.

Another hypothesis is that there are hidden confounding factors that might affect both MCI and the onset of KOA. We considered risk factors for metabolic syndrome as potential confounders. Metabolic risk factors such as hypertension and diabetes have been suggested to play a role in the pathogenesis of Alzheimer's disease as well as in the development of vascular dementia. ${ }^{22-24}$ We have also already reported the presence of hypertension and impaired glucose tolerance, and shown that accumulation of metabolic risk factors may cause the occurrence of KOA. ${ }^{25}$ These findings may indicate that the MCI is a candidate surrogate index for metabolic risk factors as a predictor of KOA occurrence. Therefore, we performed logistic regression analysis similar to that performed for model 2, with the addition of metabolic risk factors. The adjusted ORs for the occurrence of KOA in relation to the MMSE summary score or to the presence of MCI remained significant. In addition, hypertension was also significantly associated with the occurrence of KOA in relation to the MMSE summary score and the occurrence of KOA in relation to MCI, but there was no significant association between the occurrence of KOA and overweight, dyslipidaemia and impaired glucose tolerance. This result shows that components of metabolic syndrome, such as hypertension and MCI, coexist as risk factors for onset of KOA, and MCI might not be a surrogate index for metabolic risk factors for indicating the occurrence of KOA. There might be a direct or an indirect pathway between cognitive impairment and onset of $\mathrm{KOA}$, but based on the information currently available, a causal relationship between MCI and onset of KOA seems to be biologically improbable.

Besides inflammation and metabolic risk factors, there might be other hidden confounders, which could influence both MCI and OA, for example, nutritional factors. Further investigation would be needed to clarify whether the causal relationship still remains after careful consideration with analysis of other possible confounders.

There were several limitations to our study. First, although we used a standard measure of global cognitive function, we used only the MMSE to diagnose MCI, and were unable to perform additional examinations such as MRI to improve the accuracy of the diagnosis. Consequently, we may have underdiagnosed MCI. Second, we used KL grade $\geq 2$ for diagnosis of KOA. However, the KL scale is a categorical index, and it is impossible to separately evaluate osteophytosis and the minimum joint space. A computer-assisted diagnostic system for the measurement of minimum joint space width and area of osteophytosis is currently under development ${ }^{26}$ this will help measure the severity of KOA using quantitative parameters, and allow us to establish a more accurate assessment of the association between MCI and the development of OA, and facilitate early 
prevention of disability. Further, the small proportion of the population with MCI at risk for KOA onset detection might raise the bias in the results of the study.

On the contrary, the strengths of the present study include a population-based design of a cohort, large number of participants with KOA, and a 3-year follow-up with a high participation rate of $81.9 \%$. Substantial amount of detailed information, including an intervieweradministered questionnaire, dietary assessment, anthropometric measurements, neuromuscular function assessment, biochemical measurements, medical history, radiographic assessment and bone mineral density measurement, was collected at both the baseline and the second visit.

\section{CONCLUSION}

Our results indicated that MCI significantly influences the occurrence of radiographic KOA, and that KOA occurs more frequently with an decrease in the summary score of the MMSE and the presence of MCI. Prevention of MCI may be useful in preventing the occurrence of KOA and subsequent disability, while further investigation is needed to clarify whether such causalities were caused by direct or indirect associations.

\section{Author affiliations}

${ }^{1}$ Department of Joint Disease Research, 22nd Century Medical and Research Center, the University of Tokyo, Tokyo, Japan

${ }^{2}$ Department of Clinical Motor System Medicine, 22nd Century Medical and Research Center, the University of Tokyo, Tokyo, Japan

${ }^{3}$ Department of Orthopaedic Surgery, Sensory and Motor System Medicine, Graduate School of Medicine, the University of Tokyo, Tokyo, Japan

${ }^{4}$ National Rehabilitation Center for Persons with Disabilities, Saitama, Japan

Acknowledgements The authors wish to thank Dr Takako Nojiri and Mr Kazuhiro Hatanaka of the Gobo Public Health Centre; Dr Naoki Hirabayashi of the Kawakami Clinic, Hidakagawa Town; Mrs Tomoko Takijiri, Mrs Kumiko Shinou, Mrs Rie Takiguchi, Mrs Kyoko Maeda, Ms Ikuyo Ueyama, Mrs Michiko Mori, Mrs Hisayo Sugimoto, and other members of the public office in Hidakagawa Town; Dr Shinji Matsuda of the Shingu Public Health Centre; and Mrs Tamako Tsutsumi, Mrs Kanami Maeda, Mr Shoichi Shimoichi, Mrs Megumi Takino, Mrs Shuko Okada, Mrs Kazuyo Setoh, Mrs Chise Ryouno, Mrs Miki Shimosaki, Mrs Chika Yamaguchi, Mrs Yuki Shimoji, and other members of the public office in Taiji Town for their assistance in locating and scheduling participants for examinations. We also thank Ms Kyoko Yoshimura, Mrs Toki Sakurai and Mrs Saeko Sahara for their assistance with data reduction and administration.

Contributors NY conceptualised the study, was primarily responsible for developing the protocol, and acts as the guarantor for this study. SM, HO and TA conducted data collection and $\mathrm{x}$-ray assessment. All authors reviewed the protocol and contributed to interpretation of the results. All authors were involved in drafting the article and approved the final version submitted for publication. All authors had full access to all of the data in the study and take responsibility for the integrity and accuracy of the data analyses.

Funding This work was supported by Grants-in-Aid for Scientific Research B23390172 and B20390182 to NY, B23390357 and C20591737 to TA, B23390356 and C20591774 to SM, for Young Scientists A18689031 to HO, and Collaborating Research with NSF 08033011-00262 (Director, NY) from the Ministry of Education, Culture, Sports, Science, and Technology; and H17-Men-eki-009 (Director, KN), H18-Choujyu-037 (Director, Toshitaka Nakamura), H2O-Choujyu-009 (Director, NY), and H23-Chojyu-002 (Director, TA) from the Ministry of Health, Labour and Welfare in Japan. This study was also supported by grants from the Japan Osteoporosis Society (NY, SM, HO, and $T A$ ), and research aid from the Japanese Orthopaedic Association (JOA-Subsidized Science Project Research 2006-1 \& 2010-2, Director, HK).

\section{Competing interests None.}

Ethics approval Ethics approval was provided by the institutional review board at the University of Tokyo (approval number 1264).

Provenance and peer review Not commissioned; externally peer reviewed.

Data sharing statement No additional data are available.

\section{REFERENCES}

1. National Council of Aging. Fact Sheet: Chronic Disease SelfManagement. http://www.ncoa.org/assets/files/pdf/NCOA-ChronicDesease.pdf (accessed 12 Nov 2012).

2. Ministry of Health, Labour and Welfare. The outline of the results of National Livelihood Survey 2010. (http://www.mhlw.go.jp/toukei/ saikin/hw/k-tyosa//^tyousa10/4-2.html. (accessed 12 Nov 2012)

3. Launer LJ. Demonstrating the case that $A D$ is a vascular disease: epidemiologic evidence. Ageing Res Rev 2002;1:61-77.

4. Kalmijn S, Feskens EJ, Launer LJ, et al. Glucose intolerance, hyperinsulinaemia and cognitive function in a general population of elderly men. Diabetologia 1995;38:1096-102.

5. Gregg EW, Yaffe K, Cauley JA, et al. Is diabetes associated with cognitive impairment and cognitive decline among older women? Study of Osteoporotic Fractures Research Group. Arch Intern Med 2000;160:174-80.

6. Yaffe K, Barrett-Connor E, Lin F, et al. Serum lipoprotein levels, statin use, and cognitive function in older women. Arch Neurol 2002;59:378-84.

7. Yaffe $\mathrm{K}$, Weston $\mathrm{AL}$, Blackwell $\mathrm{T}$, et al. The metabolic syndrome and development of cognitive impairment among older women. Arch Neurol 2009;66:324-8.

8. Helzner EP, Luchsinger JA, Scarmeas N, et al. Contribution of vascular risk factors to the progression in Alzheimer disease. Arch Neurol 2009;66:343-8.

9. Ninomiya T, Ohara T, Hirakawa Y, et al. Midlife and late-life blood pressure and dementia in Japanese elderly: the Hisayama study. Hypertension 2011;58:22-8.

10. Petersen RC, Smith GE, Waring SC, et al. Mild cognitive impairment: clinical characterization and outcome. Arch Neurol 1999;56:303-8.

11. Yoshimura $\mathrm{N}$, Muraki S, Oka $\mathrm{H}$, et al. Prevalence of knee osteoarthritis, lumbar spondylosis and osteoporosis in Japanese men and women: the research on osteoarthritis/osteoporosis against disability study. J Bone Miner Metab 2009;27:620-8.

12. Yoshimura N, Muraki S, Oka H, et al. Cohort profile: research on Osteoarthritis/Osteoporosis Against Disability (ROAD) study. Int $J$ Epidemiol 2010;39:988-95.

13. Folstein MF, Folstein SE, McHugh PR. Mini-Mental State. A practical method for grading the cognitive state of patients for the clinician. $J$ Psychiatric Res 1975;12:189-98.

14. Anthony JC, LeResche L, Niaz U, et al. Limits of the 'Mini-Mental State' as a screening test for dementia and delirium among hospital patients. Psychological Med 1982;12:397-408.

15. Foreman MD. Reliability and validity of mental status questionnaires in elderly hospitalized patients. Nursing Res 1987:36:216-20.

16. Mori E, Mitsuya $Y$, Yamadori A. Usefulness of the Japanese version mini-mental state examination for the neurological patients. Jpn $J$ Neuropsychol 1985;33:228-35.

17. Kellgren JH, Lawrence JS eds. The epidemiology of chronic rheumatism: atlas of standard radiographs of arthritis. Oxford: Blackwell Scientific, 1963.

18. Muraki S, Akune T, Oka $\mathrm{H}$, et al. Association of radiographic and symptomatic knee osteoarthritis with health-related quality of life in a population-based cohort study in Japan: the ROAD study. Osteoarthritis Cartilage 2010;18:1227-34.

19. McGeer EG, McGeer PL. Brain inflammation in Alzheimer disease and the therapeutic implications. Curr Pharm Des 1999;5:821-36.

20. Zandi PP, Anthony JC, Hayden KM, et al. Reduced incidence of AD with NSAID but not $\mathrm{H} 2$ receptor antagonists: the Cache County Study. Neurology 2002;59:880-6.

21. Pottie $\mathrm{P}$, Presle N, Terlain B, et al. Obesity and osteoarthritis: more complex than predicted! Ann Rheum Dis 2006;65:1403-5.

22. Kalmijn S, Feskens EJ, Launer LJ, et al. Glucose intolerance, hyperinsulinaemia and cognitive function in a general population of elderly men. Diabetologia 1995;38:1096-102. 
23. Gregg EW, Yaffe K, Cauley JA, et al. Is diabetes associated with cognitive impairment and cognitive decline among older women? Study of Osteoporotic Fractures Research Group. Arch Intern Med 2000;160: 174-80.

24. Yaffe K, Barrett-Connor E, Lin F, et al. Serum lipoprotein levels, statin use, and cognitive function in older women. Arch Neurol 2002;59:378-84.
25. Yoshimura N, Muraki S, Oka $\mathrm{H}$, et al. Accumulation of metabolic risk factors such as overweight, hypertension, dyslipidaemia, and impaired glucose tolerance raises the risk of occurrence and progression of knee osteoarthritis: a 3-year follow-up of the ROAD study. Osteoarthritis Cartilage 2012;20:1217-26.

26. Oka H, Muraki S, Akune T, et al. Fully automatic quantification of knee osteoarthritis severity on plain radiographs. Osteoarthritis Cartilage 2008;16:1300-6. 